\title{
Digestive system in psoriasis: an update
}

\author{
Daniel Pietrzak ${ }^{1}$ Aldona Pietrzak ${ }^{2}$ Dorota Krasowska ${ }^{2} \cdot$ Andrzej Borzęcki $^{3} \cdot$ \\ Kinga Franciszkiewicz-Pietrzak ${ }^{4} \cdot$ Beata Polkowska-Pruszyńska $^{5}$ 『 $\cdot$ \\ Maja Baranowska $^{6} \cdot$ Kristian Reich $^{7}$
}

Received: 2 November 2016 / Revised: 21 August 2017 / Accepted: 25 August 2017 / Published online: 13 September 2017

(C) The Author(s) 2017. This article is an open access publication

\begin{abstract}
Psoriasis is a chronic inflammatory immunemediated disorder associated and often coexisting with many other immune-related clinical conditions including those affecting the gastrointestinal tract. Data obtained from the reviewed literature suggest an association between psoriasis and pathologies of the oral cavity, both psoriasis-specific lesions, as well as non-specific, such as geographic tongue or fissured tongue. These findings show the importance of thorough examination of oral mucosa in psoriatic patients. Inflammatory bowel diseases (IBD) are also linked with psoriasis. Crohn's disease and ulcerative colitis share a common genetic background, inflammatory pathways and have an evident iatrogenic anti-TNF treatment link, necessitating dermatological or gastroenterological care in patients with IBD or psoriasis, respectively, as well as treatment adjusted to manifestations. The presence of celiac disease-specific
\end{abstract}

Beata Polkowska-Pruszyńska

polkowska.beata@gmail.com

1 Department of Anaesthesiology and Intensive Care, Medical University of Lublin, Lublin, Poland

2 Chair and Department of Dermatology, Venereology and Paediatric Dermatology, Medical University of Lublin, Lublin, Poland

3 Chair and Department of Hygiene, Medical University of Lublin, Lublin, Poland

4 Department of Surgical Oncology, Medical University of Lublin, Lublin, Poland

5 Student's Scientific Association at the Department of Dermatology, Venereology and Pediatric Dermatology, Medical University of Lublin, Lublin, Poland

6 Institute of Fine Arts University of Warmia and Mazury in Olsztyn, Olsztyn, Poland

7 Dermatologikum Hamburg, Hamburg, Germany antibodies in psoriatic patients and their correlation with the severity of the disease show the association between these disorders. The linking pathogenesis comprises vitamin D deficiency, immune pathway, genetic background and increase in the intestinal permeability, which suggests a potential benefit from gluten-free diet among psoriatic patients. The link between psoriasis and non-alcoholic fatty liver disease implies screening patients for components of metabolic syndrome and lifestyle changes necessity. Some studies indicate increased prevalence of cancer in patients with psoriasis, probably due to negative influence of skin lesion impact on lifestyle rather than the role of psoriasis in carcinogenesis. However, there are no sufficient data to exclude such an oncogenic hit, which is yet to be confirmed. Therefore, all psoriasis-associated comorbidities establish the importance of a multidisciplinary approach in the treatment of these patients.

Keywords Psoriasis · Oral cavity · Geographic tongue · Inflammatory bowel disease $\cdot$ Celiac disease $\cdot$ Nonalcoholic fatty liver disease $\cdot$ Cancer

\section{Introduction}

Research evidence from the recent decade suggests that psoriasis, a chronic inflammatory immune-mediated disorder affecting ca. $2-11.4 \%$ of individuals from developed countries [125], is not an isolated pathology of the skin, but a systemic condition involving multiple organs and systems [58]. Moreover, due to similarity of pathogenic pathways, psoriasis may predispose, or at least coexist, with other genetically determined immune-mediated chronic inflammatory conditions [125]. While association of psoriasis with psoriatic arthritis and conditions forming the so-called 
Table 1 Immunometabolic components of psoriatic process include arterial hypertension, atherosclerosis, cardiovascular diseases, central obesity, dyslipidemias, insulin resistance and metabolic syndrome (in alphabetical order) of psoriatic process

Arterial hypertension

Atherosclerosis

Cardiovascular diseases

Central obesity

Dyslipidemias

Insulin resistance

Metabolic syndrome
Immunometabolic components

Table 2 Other possible components of psoriatic process include celiac disease, depressive disorders, inflammatory bowel disease (IBD), non-alcoholic fatty liver disease (NAFLD), osteoporosis, uveitis and others

Other possible components of psoriatic process

Celiac disease

Depressive disorders

Inflammatory bowel disease (IBD)

Non-alcoholic fatty liver diseases (NAFLD)

Osteoporosis

Uveitis

Others

metabolic syndrome (i.e., central obesity, insulin resistance, hypercholesterolemia, atherosclerosis, arterial hypertension, cardiovascular diseases) is well established, also a number of other entities that occur more often in psoriatic patients have been identified recently, among them inflammatory bowel disease (IBD), celiac disease, non-alcoholic fatty liver disease (NAFLD), uveitis, osteoporosis and depressive disorders [65] (Tables 1,2). While it is still unclear if psoriasis is a predisposing factor or rather a consequence of these conditions, available evidence suggests that their coexistence is not random. This makes these findings vitally important from a diagnostic and therapeutic perspective.

A review of available literature suggests that a large proportion of diseases being epidemiologically linked to psoriasis involve the gastrointestinal tract (GI) [58]. Therefore, the aim of this paper is to review published data on the GI pathologies that frequently coexist with psoriasis, their effects on natural history of this condition, potential shared pathogenic mechanisms, diagnostic and therapeutic implications.

\section{Materials and methods}

A search of Medline and EMBASE from 1966 to 2016 was carried out. The date of the last search was September 2016. The database was searched using the relevant MeSH terms including all sub-headings. The studies reporting the association between digestive system disorders and psoriasis were identified from the database by utilizing the search terms ("gastrointestinal" OR "digestive" OR "liver" OR "mouth" OR "oral cavity" OR "intestine" OR "inflammatory bowel disease" OR "Crohn's disease" OR "ulcerative colitis" OR "celiac disease" OR "gluten intolerance" OR "non-alcoholic fatty liver disease" OR "liver steatosis" OR "cancer" OR "neoplasm" OR "geographic tongue" OR "fissured tongue" OR "comorbidity") AND ("psoriasis" OR "psoriatic"). We searched for English-language publications and human studies. The database search revealed 5835 records. We chose the most representative (most insightful, explaining or suggesting the pathophysiology of the described conditions) studies and our article is not a meta-analysis.

\section{Results}

Oral cavity disorders (psoriasis-specific lesions,
geographic tongue and fissured tongue)

Although the occurrence of oral psoriatic lesions was first described by Oppenheim already in 1903 [130], the involvement of extra-dermal tissues by psoriasis has been for many years put into question [110, 175]. It was quite recently, when the term 'oral psoriasis' becomes widely accepted owing to a growing body of evidence for a systemic character of this disease [175]. While psoriatic lesions can be found virtually everywhere in the oral cavity, they most commonly involve mucosal membranes of the tongue, cheeks and gums $[55,133]$. Clinical presentation of oral psoriasis is highly heterogeneous which makes the diagnosis quite challenging [47, 175]. Furthermore, evaluation of the oral mucosa usually is not a routine component of a dermatological examination in psoriasis [133]; therefore, the true incidence of oral psoriasis may be underestimated. Mucous lesions found in the oral cavity of psoriatics can be divided into two groups: (1) psoriasis-specific lesions, and (2) non-specific lesions, present aside from psoriasis, observed also during the course of other conditions [41, 133] (Fig. 1).

The first group comprises mucosal lesions, which histological presentation is similar to that of skin psoriasis. Usually, these mucosal lesions coexist with involvement of the skin, but the cases in which oral psoriasis preceded development of dermal lesions have been reported as well [34]. Oral psoriatic lesions are highly heterogeneous. They may present as white or gray plaques, annular lesions, diffuse areas of erythema, edema, acute inflammatory infiltrate of the epithelium and mixed infiltrate of the lamina propria with neutrophils and lymphocytes, and organized neutrophilic 'micro-abscesses' [34, 47, 116] (Fig. 2). Some patients with mucosal psoriasis present with oral scarring, 


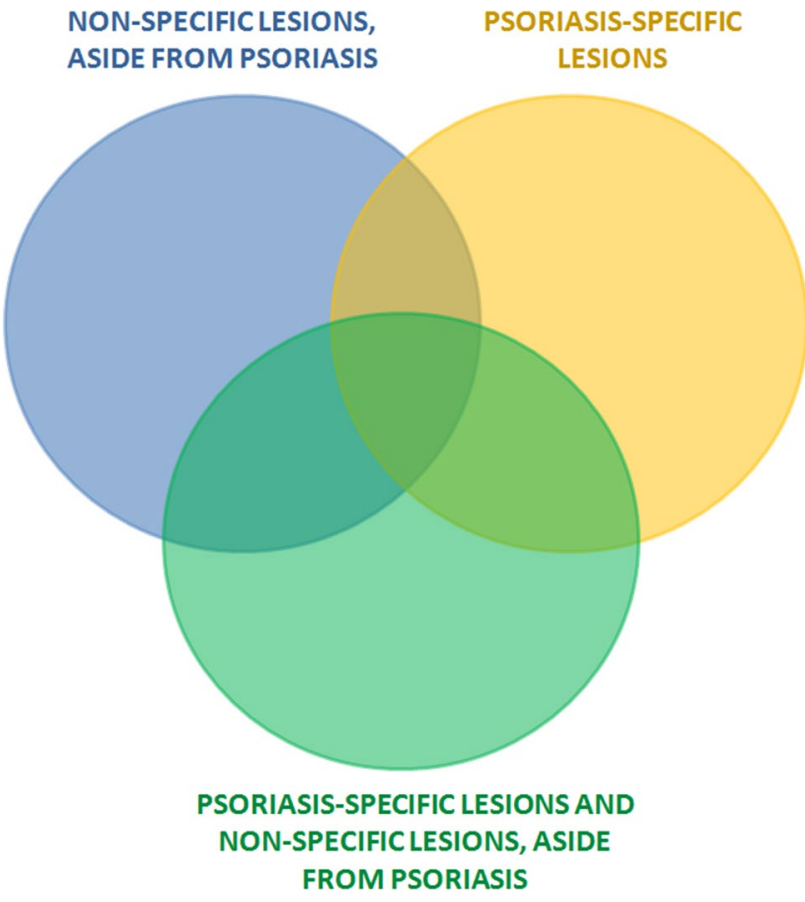

Fig. 1 Mucous lesions found in the oral cavity of psoriatics are divided into non-specific lesions, aside from psoriasis and psoriasisspecific lesions. Based on Xing et al. [171]

which could also be related to psoriasis [34]. During recent years, oral lesions that are non-specific for psoriasis, i.e., geographic tongue (GT) and fissured tongue (FT), have been gaining a growing interest from clinicians and researchers [47]. These lesions cannot be considered psoriasis specific as they do not necessarily co-exist with the skin involvement and are also observed during the course of other conditions [130]. However, a growing body of evidence from epidemiological studies, as well as the similarity of their pathogenic pathways to those involved in skin psoriasis, suggests that a link between these conditions can be stronger than previously suspected.

Geographic tongue, described for the first time by Reiter in 1831 , is a chronic inflammatory lesion of unexplained etiology $[64,77,84,180]$. GT is found in $0.6-4.8 \%$ of individuals in the general population, more often in children and slightly more frequently in women than in men; the incidence of GT decreases with age [10, 85, 117]. The condition is characterized by serpiginous white areas around the depapillated mucosa of the dorsum and sides of the tongue [127]. The white border consists of filiform papillae in regeneration and of a mixture of keratin and neutrophils, while erythematous area results from the loss of these papillae [128]. Due to its dynamic character, periodic exacerbation and remission, disappearance of lesions in one location and their simultaneous development in another, variable pattern, size and colour, GT is also referred to as benign migratory glossitis or wandering rash of the tongue [127]. The migratory character of the lesions is associated with epithelial desquamation in one location and simultaneous
Fig. 2 Clinical presentation of oral psoriasis is highly heterogeneous and may present as oral scarring, diffuse areas of erythema, edema, acute inflammatory infiltrate of the epithelium, mixed infiltrate of the lamina propria with neutrophils and lymphocytes and organized neutrophilic 'micro-abscesses'. Based on Xing et al. [171]

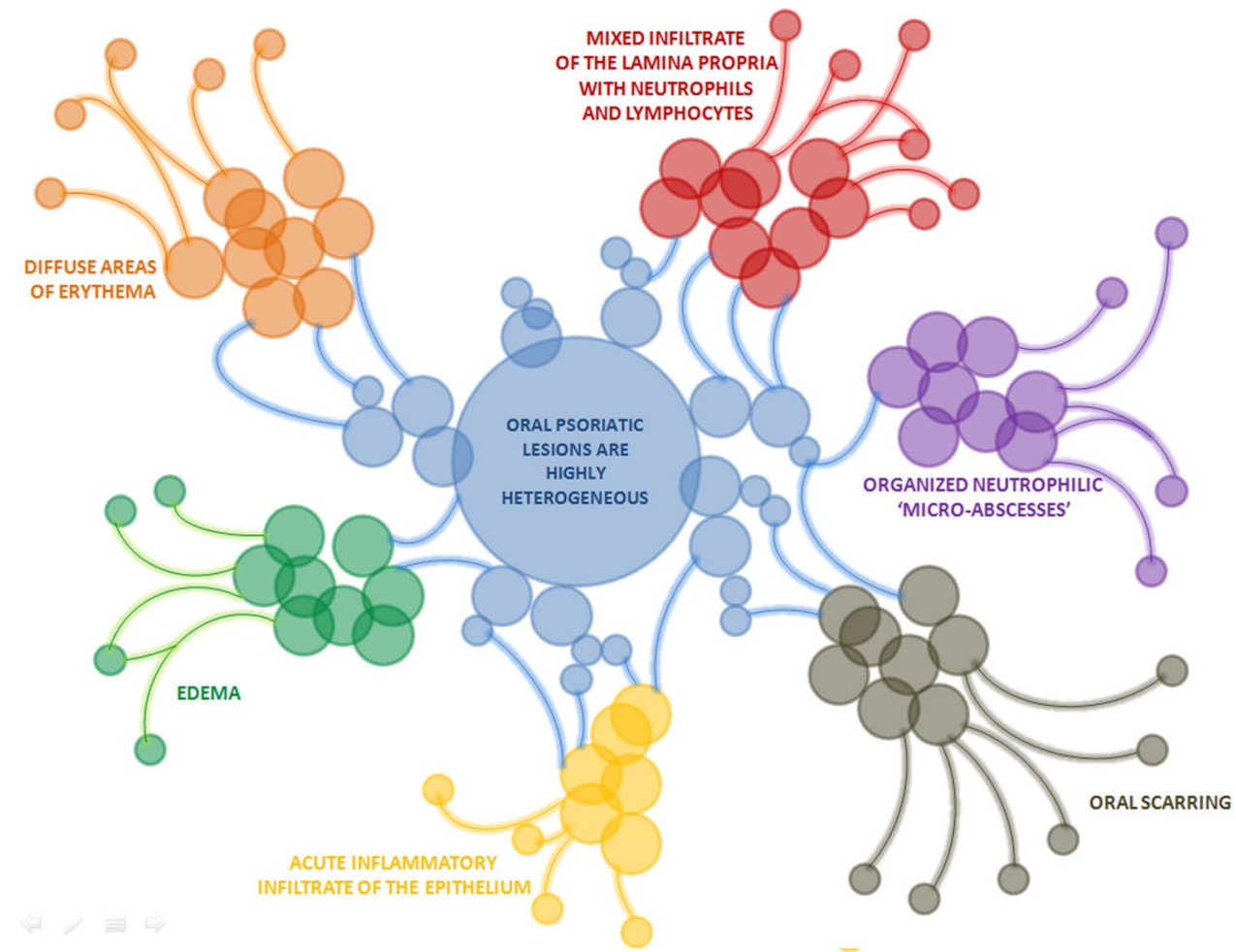


proliferation in another [64]. While GT is usually asymptomatic, some patients report pain or a burning sensation, especially during consumption of spicy or acidic foods [64, 77].

Although GT is most commonly observed in psoriasis, its coexistence with diabetes mellitus, hormonal disorders, reactive bronchitis, asthma, eczema, hay fever, atopy, elevated serum IgE, other chronic inflammatory conditions, bacterial infections, anemia, dietary deficiencies, such as vitamin B complex and iron deficiency, Reiter syndrome and Down syndrome has been reported as well [18, 182]. Further, GT can be found in some pregnant women, individuals exposed to stress and some medications, including oral contraceptives and lithium salts [5, 64, 84, 117]. Also mechanical factors, e.g., talking and chewing, may stimulate development of these lesions; this is referred to as the so-called Koebner phenomenon [128]. Nevertheless, a plethora of epidemiological studies showed that GT is most common in psoriatics [75]. The incidence of GT in psoriatic patients is estimated at 5.6-18.1\% [128]. GT was shown to be associated with an array of clinical characteristics of psoriasis, especially its severity $[37,75,150,182]$. It is typically found in younger persons and seems to be a typical feature of early-onset psoriasis [182]. Early onset psoriasis is usually considered to be more severe and more strongly associated with ungual and facial involvement as compared to the late-onset disease [178]. Consequently, GT may indirectly reflect the severity of psoriasis. Furthermore, a few studies found an association between the occurrence of GT and the severity of psoriasis expressed with PASI scores [37, 150]. Moreover, Pogrel and Cram [131] suggested that patients with acute exacerbation of psoriasis develop more oral lesions than individuals with the stable disease. Finally, according to some authors, GT is more common in subjects with generalized pustular psoriasis, i.e., more aggressive form of the disease [37, 130]. Aside from being a marker of psoriasis severity, GT seems to be also a predictor of this condition. In some published case reports, the presence of GT preceded development of skin psoriasis, especially in patients with pustular disease [37]. Interestingly, histological studies demonstrated that even in non-psoriatic patients with GT, the same histopathological features of psoriasis are present in most cases [48].

As already mentioned, a growing body of evidence points not only to epidemiological but also to a causal link between psoriasis and GT. According to some authors, GT may present similar genetic, histopathological and clinical features $[48,178]$. Both skin psoriatic lesions and GT have similar histopathologic presentation: regular increase of the spinous layer with thickening of the lower portions, thickening and swelling of papillae, suprapapillary hypotrophy with occasional presence of small spongiform pustules, absence of granular layer, parakeratosis, presence of Munro's microabscess and inflammatory cell infiltration, particularly with
T lymphocytes, macrophages and neutrophils, in the dermis and submucosa [128]. However, it should be remembered that histopathologic characteristics of both conditions may vary depending on clinical stage of the lesion and the biopsied area [48]. Despite the unknown etiology, some authors suggest that there is a genetic link between psoriasis and GT. One of the most well-known genetic factors of susceptibility for psoriasis is the human leukocyte antigen (HLA), located on the short arm of chromosome 6.46 [101]. Indeed, few studies demonstrated a link between GT and $\mathrm{HLACw}^{*} 06$, the main allele of susceptibility to psoriasis [63, 128]. Also indirect proof for a common genetic background of GT and psoriasis exists: early onset psoriasis, often co-existing with GT, was shown to be more often associated with HLA-C*06 than the late-onset disease $[9,177]$. Involvement of the same genetic factors in the etiopathogenesis of GT and psoriasis is also reinforced by the fact that $35 \%$ of patients with GT and psoriasis have a positive family history [176]. Aside from a potential link to HLA, also the presence of the polymorphism +3954 IL-1B was shown to be associated with increased risk of GT [68]; the product of the altered gene, interleukin 1B (IL-1B), is known to play a pivotal role in the pathogenesis of psoriasis as well [128]. Another argument for a pathogenic link between GT and psoriasis may be the fact that in one study, patients with the former condition presented with elevated salivary concentrations of tumor necrosis factor alpha (TNF-alpha) and interleukin 6 (IL-6), i.e., cytokines implicated in the pathogenesis of psoriasis [5].

Also environmental influences seem to play a role in the development of GT in psoriatics. GT is known to be linked to alcohol consumption and stress, and psoriatic patients are exposed to these two factors to a markedly larger extent than individuals from the general population [61]. Some studies demonstrated that GT develops less often in cigarette smokers due to smoking-related changes in the tongue epithelium: enhanced keratinization and a decrease in the synthesis of TNF-alpha, IL-1 and IL- 6 by macrophages, associated with activation of nicotine receptors in these cells [26, 61, 77]. While the role of smoking as a factor protecting against the development of GT is still unestablished, it was already confirmed in other oral diseases, such as aphthous stomatitis $[11,163]$. Considering that neutrophils play a key role in both psoriasis and aphthous stomatitis, perhaps morphological and functional changes in these cells caused by cigarette smoking [94] have a role in this protection mechanism. If this is true, a large proportion of smokers among psoriatics may at least partially explain why GT is found in only less than $20 \%$ of this group.

Fissured tongue is another non-specific oral pathology found in $6-47.5 \%$ of psoriatic patients [47, 131, 182]. FT, also referred to as lingua fissurata, lingua plicata, scrotal tongue or grooved tongue, is recognized clinically by an anteroposterior groove, often with multiple lateral fissures 
[182]. The frequency of FT increases with age [49, 74] and is usually higher among men [38, 43]. Epidemiological studies demonstrated that aside from psoriasis, FT is also found in patients with acromegaly, Sjögren's, Down and Melkersson-Rosenthal syndromes [138].

Compared to GT, our knowledge about the link between FT and psoriasis is fairly limited. While GT is a transient lesion, FT seems to be a permanent pathology of the tongue [165]. Furthermore, a specific sequence, with the development of GT in early psoriasis and manifestation of FT at further stages of the disease, has been reported by some authors [129]. However, it appears that there is no significant difference in the occurrence of FT in early and late-onset psoriasis [182]. This may be explained, at least in part, by the fact that the incidence of this condition increases with age [182]. According to some authors, likewise GT, also FT is more common in generalized pustular psoriasis [37]. Despite familial occurrence of both GT and FT [62], no genetic background for the former pathology was found in psoriatic patients [34, 62]. Consequently, when associated with GT, FT seems to be a sequel of the latter [130].

In conclusion, the abovementioned data about the coexistence of psoriasis with non-specific oral lesions have some important clinical implications. First of all, thorough evaluation of oral mucosa should become a routine component of a dermatological examination. Whenever suspected lesions are found in the psoriatic with psoriasis, differential diagnosis should be conducted to exclude candidiasis, lichen planus, erythroplasia, systemic lupus erythematosus (SLE), trauma, drug reactions and other potential non-psoriatic etiologies [10]. If all these conditions are excluded based on clinical and whenever necessary, also histopathologic examination, modification of anti-psoriatic treatment may be considered, since a scarce evidence from individual case reports suggests that psoriatic patients with concomitant GT and/or FT may respond well to systemic treatment with retinoids or antiTNF agents [24, 41].

\section{Inflammatory bowel disease}

Inflammatory bowel disease (IBD), i.e., Crohn's disease (CD) and ulcerative colitis (UC), develops due to inappropriate immune response to commensal microorganisms in genetically predisposed individuals $[58,141,154,168$, 169]. A review of literature showed three potential epidemiologic links between IBD and psoriasis: (1) higher incidence of secondary psoriasis in patients with CD or UC, (2) predisposition to IBD among psoriatics, and (3) induction of iatrogenic psoriatic lesions in IBD patients treated with anti-TNF agents.

The first data on a potential link between the two conditions originate from 1968 when the prevalence of psoriasis in first-degree relatives of patients with $\mathrm{CD}$ was shown to be two to threefold higher than in the controls [70]. Further studies confirmed that individuals with IBD and their close relatives are predisposed to the development of psoriatic lesions to a markedly larger extent than subjects from the general population, and the incidence of psoriasis in the former group can be even up to fivefold higher [96]. This association was observed irrespective of the age at which the diagnosis of IBD was made, intestinal segment involved and patient sex [96]. Also an inverse phenomenon has been observed, i.e., higher incidence of IBD in psoriatics [30]. Available evidence suggests that the risk of $\mathrm{CD}$ and UC during the course of psoriasis is more than twofold and nearly twice higher than in the general population, respectively, also after exclusion of patients treated with anti-TNF agents [30]. Furthermore, some studies demonstrated that despite the lack of clinical abnormalities, psoriatic patients may present with microscopic evidence of intestinal inflammation and elevated levels of pANCA, i.e., the features of a latent IBD [87, 100, 166]. Indeed, there is a case report of a patient with psoriasis who developed clinical CD after up to 15 years since diagnosis of the primary condition. The authors of this report hypothesized that it was previous antipsoriatic treatment which likely masked the clinical symptoms of IBD and contributed to the diagnostic delay [158].

The above-mentioned associations can be at least partially explained by a common genetic background of psoriasis and IBD. Several areas of chromosomes 16, 6, 4 and 3 were found to contain common genetic markers of psoriasis and IBD [22, 28, 45, 78, 79, 109, 119, 121, 145, 174]. All loci determining susceptibility to both conditions, among them the IBD3 locus involved in CD and UC, and PSORS1 locus involved in psoriasis, were found in the 6P21 region encompassing the major histocompatibility complex (MHC) [170]. Aside from the MHC components, also a few other genes, specifically those encoding interleukin 23 receptor (IL-23R) and interleukin 12B (IL-12B) were implicated in the pathogenesis of both psoriasis and IBD $[21,44]$. Furthermore, both diseases share some common inflammatory pathways. Both psoriasis and IBD are Th1mediated inflammatory disorders associated with enhanced synthesis of cytokines, TNF-alpha and interferon-gamma (IFN-gamma). Also Th17 cells, synthesizing interleukins-17 and -21 (IL-17 and IL-21), as well as IFN-gamma, play a pivotal role in the pathogenesis of both conditions [7, 156, 173]. Th17 cells promote acanthosis, hyperkeratosis, and parakeratosis, as well as the synthesis of inflammatory molecules within the dermis and epidermis $[8,50]$. In psoriatic patients, biopsy specimens from injured skin showed a high number of Th17 [95, 142]. Aside from elevated serum concentrations of IL-17 and IL-23, increased levels of these cytokines were also found in the intestinal lamina propria of individuals with $\mathrm{CD}$ and in the skin lesions of psoriatic patients [42]. Also abnormalities in the number and function 
of T-regulatory lymphocytes (T-regs) have been described in both psoriasis and IBD [152] (Fig. 3). In the active phase of $\mathrm{CD}$ and $\mathrm{UC}$, the number of T-regs in peripheral blood is lower than in the controls; this phenomenon is not observed during remission of these conditions, suggesting that in the course of IBD, T-regs migrate from peripheral blood to the inflamed intestinal mucosa [144, 179]. An altered recruitment and/or function of T-regs can be also an important pathogenic factor in skin diseases, including psoriasis, although the exact mechanisms are yet to be established $[16,76]$.

As already mentioned, there is also an evident iatrogenic link between IBD and psoriasis. A number of authors reported that some patients with IBD may develop psoriatic lesions during the course of anti-TNF treatment, with either etanercept or anti-TNF antibodies, such as infliximab (IFX) or adalimumab (ADA) [35, 67, 157]. This phenomenon is seemingly paradoxical, as anti-TNF agents are also effective in psoriatics $[66,111,146]$. Epidemiologic data suggest that this side effect is unlikely related to common genetic and pathogenic backgrounds of both conditions; a latency period between the development of secondary non-iatrogenic psoriasis is longer, usually up to a few years [157]. Although highly variable (ranging from days to even 4 years), mean time elapsed since the initiation of an anti-TNF treatment to the onset of psoriatic lesions was estimated at 10.5 months in a review of 127 reported cases [90]. Furthermore, development of the secondary psoriatic lesions was observed not only in patients receiving anti-TNF agents due to IBD, but also in individuals who received drugs from this group due to the presence of other immune-mediated conditions, such as rheumatoid arthritis (RA), ankylosing spondylitis and juvenile arthritis $[32,90,171]$. The incidence of psoriasis during anti-TNF treatment for various clinical conditions has been estimated at $0.6-5.3 \%[73,90]$, and at $1.6-2 \%$ in patients who received anti-TNF agents due to $\operatorname{IBD}[13,135]$. A greater absolute frequency of psoriasis cases has been reported with the use of IFX than with ADA or etanercept in the treatment of IBD [67]. The onset of psoriatic lesions during anti-TNF treatment can follow three primary patterns: (1) psoriasiform eruption with typical histopathological features of a drug reaction, showing lichenoid or interface dermatitis, (2) exacerbation of preexisting psoriasis, and (3) de novo psoriasis [169]. When the skin lesions develop in patients with a history of psoriasis, they are usually found in a previously unaffected location and often have an atypical appearance [35].

Although Il-17 serum is elevated both in psoriasis and $\mathrm{CD}$, while anti-TNFs work in both psoriasis and IBD, antiIL17 works in psoriasis but not in IBD and may even exacerbate IBD. This strengthens the importance of the link between psoriasis and IBD $[35,51,67]$.

According to most authors, there is an increase in interferon-alpha (IFN-alpha) level due to reduced concentration of circulating TNF-alpha, which leads to the development of psoriatic lesions [120, 124]. Indeed, some studies demonstrated that the secondary psoriatic lesions developed during the course of anti-TNF treatment contain higher levels of IFN-alpha than those associated with idiopathic psoriasis [40, 54]. Furthermore, treatment with IFN-alpha, either systemic or topical, was shown to exacerbate psoriasis [56, 93]. Other proposed underlying mechanisms of secondary psoriasis include anti-TNF treatment-induced activation of autoreactive T-cells $[90,147]$ or certain infectious agents
Fig. 3 Mechanisms enhancing an increase of intestinal permeability in inflammatory bowel disease IBD involve several group of cells-dendritic cells "in situ in the intestinal wall", T-regulatory lymphocytes (T-reg), Th17 cells, Th1 cells, which are responsible for producing cytokines such as IFN $\gamma$, INF $\alpha$, Il-6, IL-12, IL-23 and IL-17. Based on Vlachos et al. [167]

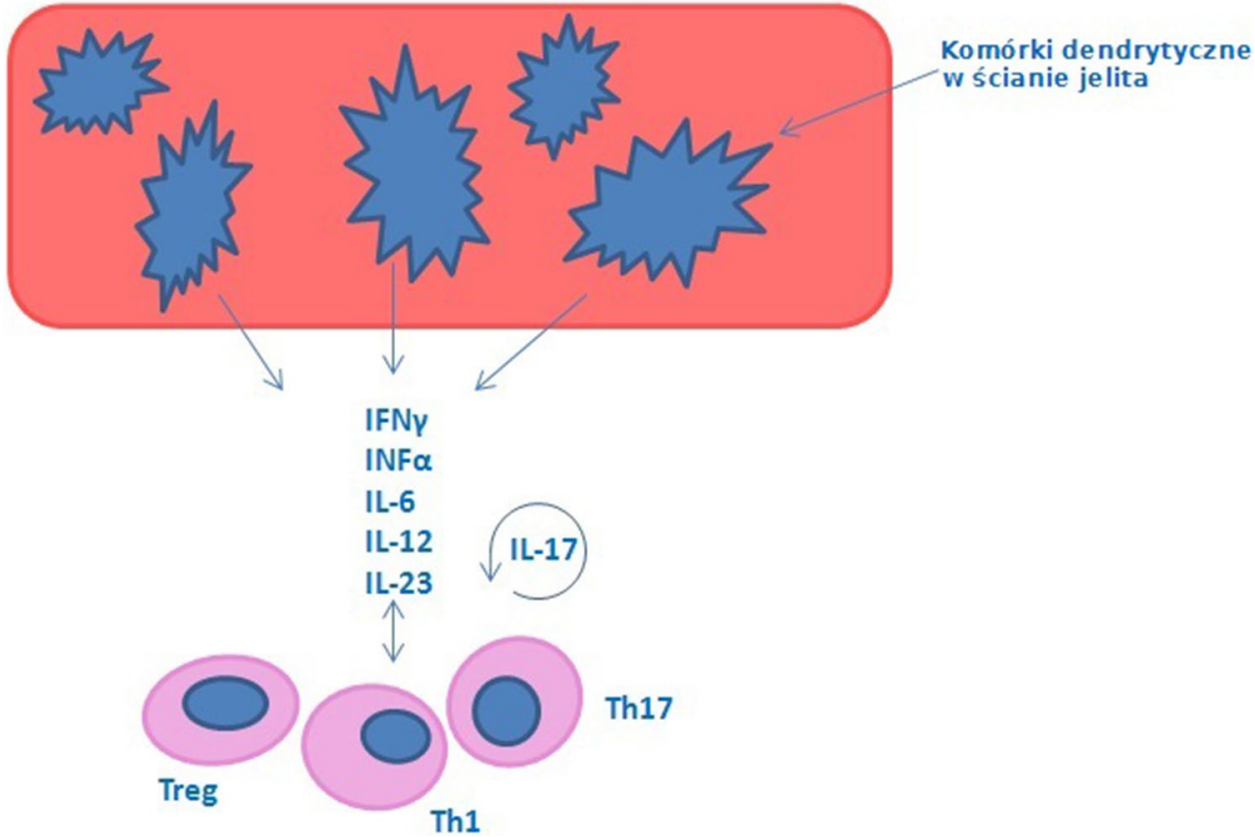


such as Streptococcus spp. [12, 90, 97]. Interestingly, the incidence of palmoplantar pustulosis in patients treated with anti-TNF agents was shown to be at least twice as high as in the general population (40 vs. less than 20\%) [90]. It has been suggested that this may be due to the high expression of TNF-alpha in the palmar eccrine sweat ducts [114]. There seems to be a genetic predisposition to secondary psoriasis as well, since the vast majority of patients receiving antiTNF treatment do not develop skin lesions [35]. However, most patients with secondary psoriasis do not have a family history of this condition [82, 90, 135, 181]. While one study demonstrated that patients with anti-TNF treatmentassociated secondary psoriasis had modestly greater genetic predisposition towards the latter condition, no single causative polymorphism was identified [167]. Also a contribution of an environmental factor cannot be excluded owing to the previously mentioned heterogeneity in the time elapsed since the initiation of anti-TNF treatment to the onset of psoriatic lesions.

Irrespective of the etiology thereof, the hereby presented associations between IBD and psoriasis have some important clinical implications. First, the hereby presented data suggest that individuals with CD or UC should be regularly followed up by a dermatologist and thoroughly examined for the presence of potential psoriatic lesions, especially during the course of anti-TNF treatment and thereafter. The same refers to patients with psoriasis, in whom information on potential GI ailments suggestive of IBD should be obtained during each control visit, and gastroenterological consultation should be sought whenever necessary. Available evidence suggests that patients who developed secondary psoriasis during the course of anti-TNF treatment for IBD should probably continue the therapy [67]. Experiences of other authors imply that discontinuance of anti-TNF agents may result in exacerbation of the primary condition, and topical treatment is sufficient to control secondary psoriasis in most cases [31]. However, discontinuation of the antiTNF agent should be considered in patients who did not respond adequately to local treatment of psoriatic lesions. Such approach, with maintenance of either topical or systemic treatment for psoriasis (methotrexate, retinoids or cyclosporine), proved to be adequate in patients with severe psoriatic lesions covering more than $5 \%$ of the body surface area, and in individuals with pustulosis [31]. When secondary psoriatic lesions are not severe but negatively affect the patient's quality of life, temporary suspension of the biological agent with subsequent reintroduction with strict clinical monitoring may be an option [67].

\section{Celiac disease}

Celiac disease is an autoimmune condition triggered by ingestion of gluten in genetically predisposed individuals
[137]. Aside from GI ailments, this systemic disease, affecting ca. $1 \%$ of the general population, may also predispose to the development of skin lesions, endocrine disorders, iron deficiency anemia, osteoporosis, hypertransaminasemia, neurological disorders and even cancer [141]. The presence of celiac disease-specific antibodies against gliadin, reticulin, glutaminase and smooth muscle endomysium was also reported in subjects with psoriasis and other autoimmune and inflammatory conditions, such as SLE, RA and Sjögren's syndrome [23, 36, 83, 102, 113, 123, 136]. Importantly, the level of these antibodies was shown to correlate with the severity of psoriasis [172]. Aside from this serological evidence, also epidemiologic links between psoriasis and celiac disease have been documented [2, 14, 122]. According to various authors, $0.2-4.3 \%$ of psoriatics may present with concomitant celiac disease, and odds ratios for coexistence of these two conditions were consistently shown to be around 2 [2, 14, $106,118,122]$. Importantly, a large nationwide study demonstrated that subjects with celiac disease are at increased risk of psoriasis both before and after the diagnosis of gluten intolerance [106]. However, epidemiologic evidence is still inconclusive, since some studies did not demonstrate an association between psoriasis and celiac disease, either at a clinical or serological level [33, 89]. Furthermore, several studies that documented such a link suffered from limitations including small numbers of patients with celiac disease and lack of a control group [162].

If it truly exists, the association between celiac disease and psoriasis may be explained by several mechanisms. First, malabsorption associated with celiac disease may predispose to vitamin D deficiency [15]; also gluten-free diet used in the treatment of celiac disease is often deficient, regarding in this vitamin [92]. Vitamin D deficiency is known to predispose to psoriasis, and exposure to sun light and administration of topical vitamin D analogs in creams produced beneficial effects in psoriatic patients [98]. Second, although celiac disease is generally associated with Th2 response, also Th1 and Th17 cells [29, 99, 143], i.e., the lymphocyte subpopulations involved in the development of psoriasis, play an important role in the pathogenesis of this condition [91]. Recently, Skavland et al. [151] demonstrated that some wheat antigens may trigger an immune response in psoriatic patients significantly more often than in non-psoriatic controls, inducing expression of cutaneous lymphocyte antigen (CLA). Third, also a common genetic background may explain the link between psoriasis and celiac disease. Genome-wide association studies of these two conditions identified genetic susceptibility loci at eight genes regulating innate and adaptive immune response: TNFAIP3, RUNX3, ELMO1, ZMIZ1, ETS1, SH2B3, SOCS1 and UBE2L3 [105, $159,161]$. The fourth implicated mechanism may be associated with an increase in the intestinal permeability [3], a 
characteristic feature of celiac disease that has been also found in some psoriatics [80] (Table 3).

Although available data regarding coexistence of celiac disease and psoriasis are still inconclusive and potential shared etiopathogenic mechanisms remain mostly hypothetical, a large body of evidence suggests that psoriatic patients, either with concomitant celiac disease or asymptomatic gluten intolerance, may benefit from gluten-free diet. In a study of psoriatic patients who tested positively for anti-gliadin antibodies (AGA), 3-month gluten-free diet resulted in a significant decrease in the affected area of the skin, PASI scores and AGA titers [113]. Interestingly, ca. 50\% of the AGA-positive patients did not show endoscopic evidence of celiac disease prior to implementation of the gluten-free diet, which suggests that such diet may be also beneficial in psoriatics with asymptomatic gluten sensitivity [25]. Also in another study, implementation of a gluten-free diet resulted in a decrease in tissue transglutaminase expression in AGApositive patients with psoriasis [112]. Finally, a few case reports documented complete resolution of skin lesions after administration of gluten-free diet to psoriatics with serological evidence of gluten intolerance $[4,39,53,69]$. Altogether, these findings suggest that gluten-free diet may produce beneficial effects in most psoriatic patients who tested positively for celiac disease-specific antibodies.

To summarize, relatively frequent coexistence of celiac disease and psoriasis justifies monitoring of patients with either condition for clinical evidence of the other. Furthermore, serum levels of vitamin D should be regularly controlled in patients with celiac disease, either with concomitant psoriasis or without. Even more importantly, implementation of gluten-free diet should be considered in psoriatics presenting with serological evidence of gluten intolerance or clinical signs of celiac disease.

\section{Non-alcoholic fatty liver disease}

Non-alcoholic fatty liver disease (NAFLD) is a heterogeneous condition including both relatively benign simple fatty liver and severe non-alcoholic steatohepatitis, which may eventually result in fibrosis and cirrhosis and give rise to hepatocarcinoma [58]. NAFLD is diagnosed in $20-30 \%$ of individuals from the general population, and represents an

Table 3 Links between psoriasis and celiac disease

Association between celiac disease and psoriasis

Vitamin D deficiency

Th2 response, also Th1 and Th17 cells [expression of cutaneous lymphocyte antigen (CLA)]

Genetic background

Increase in the intestinal permeability established cardiovascular risk factor and common manifestation of the metabolic syndrome also usually coexists with insulin resistance $[104,155]$.

Owing to the frequent occurrence of the metabolic syndrome in psoriatic patients, high incidence of NAFLD in this group is not surprising. Available evidence suggests that the risk of NAFLD in psoriatics is approximately twice as high as in the general population $(48-59 \%)$ [58, 60, 115]. Importantly, this association seems to occur independently of the administration of potentially hepatotoxic anti-psoriatic medications, such as methotrexate and anti-TNF agents [60]. Furthermore, the results of several studies imply that whenever they coexist in the same patient, psoriasis and NAFLD may perpetuate the course of each other. The presence of NAFLD was shown to be associated with greater severity of psoriasis and a higher risk of joint involvement. In turn, individuals with NAFLD and concomitant psoriasis were more prone to the development of liver fibrosis than nonpsoriatic controls [115].

The etiopathogenic link between psoriasis and NAFLD is not straightforward, as recently both these entities have been increasingly recognized as systemic conditions. Some pro-inflammatory cytokines synthesized by lymphocytes and keratinocytes in psoriatic skin, including IL-6, IL-17 and TNF-alpha, may contribute to systemic insulin resistance [148, 164], a common feature of NAFLD. Another important contributor is inflamed visceral adipose tissue (VAT) that perpetuates both chronic inflammation and liver damage due to enhanced secretion of various factors, such as non-esterified fatty acids, hormones and pro-inflammatory adipokines (TNF-alpha, IL-6, visfatin, leptin and resistin), as well as due to decreased production of adiponectin $[19,20,81,103,149]$. As a result, the liver of obese and/ or insulin-resistant individuals is exposed to high plasma concentrations of non-esterified fatty acids, being a principal factor of oxidative and cytokine-induced liver damage $[19,20,81,103,149]$. Although this relationship has not been yet confirmed experimentally, enhanced release of non-esterified fatty acids from inflamed VAT may also contribute to the development of psoriasis [107]. On the other hand, NAFLD, especially its more severe forms, may aggravate insulin resistance, predispose to dyslipidemia and enhance synthesis of pro-inflammatory, pro-coagulant, prooxidant and pro-fibrogenic mediators (CRP, IL-6, fibrinogen, plasminogen activator inhibitor 1 and tumor growth factor beta) in the liver $[6,19,20,153]$. All these factors may be involved in the pathogenesis of psoriasis, stimulating proliferation of keratinocytes, skin inflammation and synthesis of various adhesion molecules [107]. Also the role of environmental and iatrogenic factors should be considered in this vicious circle. For example, cigarette smoking and alcohol consumption, both common among psoriatics, may predispose to NAFLD and enhance liver fibrosis, as well as 
directly interfere with the course of psoriasis [1]. In turn, many systemic anti-psoriatic medications, especially methotrexate, may contribute to iatrogenic damage of hepatocytes, liver steatosis and fibrosis, whereas long-term administration of steroids is an established risk factor of insulin resistance, diabetes mellitus, obesity and hyperlipidemia $[46,57,59$, $72,88,139]$.

The unquestioned link between psoriasis and metabolic syndrome, including its liver component, NAFLD, has important clinical implications. First, all psoriatic patients should be regularly screened for all components of the metabolic syndrome and encouraged to lifestyle modifications, such as dietary changes, weight control and greater involvement in physical activity. Secondly, liver function should be thoroughly monitored during the course of anti-psoriatic treatment, and the therapeutic protocol should be modified appropriately whenever any evidence of impaired hepatic function emerged.

\section{Psoriasis and cancer}

The chronic and immune-mediated character of the primary condition, iatrogenic factors (long-term administration of immunosuppressive agents, phototherapy) and greater exposure to some established environmental carcinogens (cigarette smoke, alcohol) may predispose psoriatic patients to carcinogenesis, also within the GI tract [132]. Indeed, several epidemiologic studies including one large meta-analysis, demonstrated that psoriasis is associated with increased evidence of cancer overall [17, 27, 52, 108, 134], and may predispose to the development of GI malignancies, specifically oral, esophageal, liver and pancreatic cancer [17, 52, $71,86,126,160]$. However, psoriasis was no longer associated with the excess cancer risk whenever the results were adjusted for cigarette smoking and alcohol consumption data, if available [17, 134].

Based on available evidence, psoriatic patients may be at an increased risk of carcinogenesis within the GI tract, but the excess incidence of cancers in this location does not seem to be related to the biology of the primary condition or treatment thereof, but rather to the negative impact of skin lesions on lifestyle. However, it cannot be excluded that the increased risk of carcinogenesis in psoriatics may be also attributed to concomitant GI pathologies presented in this review, specifically IBD, NAFLD and celiac disease, since all of them are known to predispose to cancer. However, to the best of our knowledge, this association has not been studied thus far. Nevertheless, individual risk of cancer should be estimated for each psoriatic patient, taking into account both general risk factors, such as age, family history, environmental and occupational exposures, and disease-specific factors, such as anti-psoriatic treatments and comorbidities.

\section{Discussion}

1. Published evidence summarized in this review suggests that psoriasis is considered as a systemic condition and may co-exist with numerous GI pathologies, especially those with established immune-related mechanisms.

2. Predisposition to some diseases of the GI may be associated with anti-psoriatic treatment.

3. It seems that psoriatic patients may be at a high risk of carcinogenesis within digestive tract but this issue requires further researches.

Acknowledgements The authors would like to thank Professor Ioannis D. Bassukas for consulting the figure preparations.

\section{Compliance with ethical standards}

Conflict of interest The authors declare that they have no conflict of interest.

Funding Medical University of Lublin-University Grant DS 168, Grant recipient-Aldona Pietrzak.

Ethical approval This article does not contain any studies with human participants or animals performed by any of the authors.

Open Access This article is distributed under the terms of the Creative Commons Attribution 4.0 International License (http://creativecommons.org/licenses/by/4.0/), which permits unrestricted use, distribution, and reproduction in any medium, provided you give appropriate credit to the original author(s) and the source, provide a link to the Creative Commons license, and indicate if changes were made.

\section{References}

1. Abedini R, Salehi M, Lajevardi V, Beygi S (2015) Patients with psoriasis are at a higher risk of developing nonalcoholic fatty liver disease. Clin Exp Dermatol 40(7):722-727. doi:10.1111/ ced.12672 (Epub 2015 May 11)

2. Abenavoli L, Leggio L, Ferrulli A, Vonghia L, Gasbarrini G, Addolorato G (2005) Association between psoriasis and coeliac disease. Br J Dermatol 152(6):1393-1394. doi:10.1111/j.1365-2133.2005.06636.x

3. Abenavoli L, Proietti I, Zaccone V, Gasbarrini G, Addolorato G (2009) Celiac disease: from gluten to skin. Expert Rev Clin Immunol 5(6):789-800. doi:10.1586/eci.09.46

4. Addolorato G, Parente A, de Lorenzi G, D'Angelo Di Paola ME, Abenavoli L, Leggio L, Capristo E, De Simone C, Rotoli M, Rapaccini GL, Gasbarrini G (2003) Rapid regression of psoriasis in a coeliac patient after gluten-free diet. A case report and review of the literature. Digestion 68(1):9-12. doi:10.1159/000073220

5. Alikhani M, Khalighinejad N, Ghalaiani P, Khaleghi MA, Askari E, Gorsky M (2014) Immunologic and psychologic parameters associated with geographic tongue. Oral Surg Oral Med Oral Pathol Oral Radiol 118(1):68-71. doi:10.1016/j. oooo.2014.03.007 
6. Anstee QM, Targher G, Day CP (2013) Progression of NAFLD to diabetes mellitus, cardiovascular disease or cirrhosis. Nat Rev Gastroenterol Hepatol 10(6):330-344. doi:10.1038/ nrgastro.2013.41

7. Asarch A, Barak O, Loo DS, Gottlieb AB (2008) Th17 cells: a new paradigm for cutaneous inflammation. J Dermatol Treat 19(5):259-266. doi:10.1080/09546630802206686

8. Asarch A, Barak O, Loo DS, Gottlieb AB (2008) Th17 cells: a new therapeutic target in inflammatory dermatoses. J Dermatol Treat 19(6):318-326. doi:10.1080/09546630802206660

9. Aslanian FM, Lisboa FF, Iwamoto A, Carneiro SC (2005) Clinical and epidemiological evaluation of psoriasis: clinical variants and articular manifestations. J Eur Acad Dermatol Venereol 19(1):141-142. doi:10.1111/j.1468-3083.2004.01102.x

10. Assimakopoulos D, Patrikakos G, Fotika C, Elisaf M (2002) Benign migratory glossitis or geographic tongue: an enigmatic oral lesion. Am J Med 113(9):751-755. doi:10.1016/ S0002-9343(02)01379-7

11. Atkin PA, $\mathrm{Xu} \mathrm{X}$, Thornhill $\mathrm{MH}$ (2002) Minor recurrent aphthous stomatitis and smoking: an epidemiological study measuring plasma cotinine. Oral Dis 8(3):173-176. doi:10.1034/j.1601-0825.2002.01826.x

12. Baeten D, Kruithof E, Van den Bosch F, Van den Bossche N, Herssens A, Mielants H, De Keyser F, Veys EM (2003) Systematic safety follow up in a cohort of 107 patients with spondyloarthropathy treated with infliximab: a new perspective on the role of host defence in the pathogenesis of the disease? Ann Rheum Dis 62(9):829-834. doi:10.1136/ard.62.9.829

13. Bernstein CN, Wajda A, Blanchard JF (2005) The clustering of other chronic inflammatory diseases in inflammatory bowel disease: a population-based study. Gastroenterology 129(3):827836. doi:10.1053/j.gastro.2005.06.021

14. Birkenfeld S, Dreiher J, Weitzman D, Cohen AD (2009) Coeliac disease associated with psoriasis. Br J Dermatol 161(6):13311334. doi:10.1111/j.1365-2133.2009.09398.x

15. Bodé S, Hassager C, Gudmand-Høyer E, Christiansen C (1991) Body composition and calcium metabolism in adult treated coeliac disease. Gut 32(11):1342-1345. doi:10.1136/gut.32.11.134

16. Bovenschen HJ, van Vlijmen-Willems IM, van de Kerkhof PC, van Erp PE (2006) Identification of lesional CD4+ CD25+ Foxp3+ regulatory T cells in Psoriasis. Dermatology 213(2):111-117. doi:10.1159/000093849

17. Brauchli YB, Jick SS, Miret M, Meier CR (2009) Psoriasis and risk of incident cancer: an inception cohort study with a nested case-control analysis. J Invest Dermatol 129(11):2604-2612. doi:10.1038/jid.2009.113

18. Bruce AJ, Rogers RS (2003) Oral psoriasis. Dermatol Clin 21(1):99-104. doi:10.1016/S0733-8635(02)00065-7

19. Byrne CD, Targher G (2014) Ectopic fat, insulin resistance, and nonalcoholic fatty liver disease: implications for cardiovascular disease. Arterioscler Thromb Vasc Biol 34(6):1155-1161. doi:10.1161/ATVBAHA.114.303034

20. Byrne CD, Targher G (2015) NAFLD: a multisystem disease. J Hepatol 62(1 Suppl):47-64. doi:10.1016/j.jhep.2014.12.012

21. Capon F, Di Meglio P, Szaub J, Prescott NJ, Dunster C, Baumber L, Timms K, Gutin A, Abkevic V, Burden AD, Lanchbury J, Barker JN, Trembath RC, Nestle FO (2007) Sequence variants in the genes for the interleukin-23 receptor (IL23R) and its ligand (IL12B) confer protection against psoriasis. Hum Genet 122(2):201-206. doi:10.1007/s00439-007-0397-0

22. Capon F, Munro M, Barker J, Trembath R (2002) Searching for the major histocompatibility complex psoriasis susceptibility gene. J Invest Dermatol 118(5):745-751. doi:10.1046/j.1523-1747.2002.01749.x

23. Cardinali C, Degl'innocenti D, Caproni M, Fabbri P (2002) Is the search for serum antibodies to gliadin, endomysium and tissue transglutaminase meaningful in psoriatic patients? Relationship between the pathogenesis of psoriasis and coeliac disease. Br J Dermatol 147(1):187-188

24. Casper U, Seiffert K, Dippel E, Zouboulis CC (1998) Exfoliatio areata linguae et mucosae oris: a mucous membrane manifestation of psoriasis pustulosa? Hautarzt 49(11):850-854. doi:10.1007/s001050050837

25. Chalmers RJ, Kirby B (2000) Gluten and psoriasis. Br J Dermatol 142(1):5-7. doi:10.1046/j.1365-2133.2000.03345.x

26. Chandran V, Raychaudhuri SP (2010) Geoepidemiology and environmental factors of psoriasis and psoriatic arthritis. J Autoimmun 34(3):24. doi:10.1016/j.jaut.2009.12.001

27. Chen YJ, Wu CY, Chen TJ, Shen JL, Chu SY, Wang CB, Chang YT (2011) The risk of cancer in patients with psoriasis: a population-based cohort study in Taiwan. J Am Acad Dermatol 65(1):84-91. doi:10.1016/j.jaad.2010.04.046

28. Cho JH, Nicolae DL, Gold LH, Fields CT, LaBuda MC, Rohal PM, Pickles MR, Qin L, Fu Y, Mann JS, Kirschner BS, Jabs EW, Weber J, Hanauer SB, Bayless TM, Brant SR (1998) Identification of novel susceptibility loci for inflammatory bowel disease on chromosomes 1p, 3q, and 4q: evidence for epistasis between 1p and IBD1. Proc Natl Acad Sci USA 95(13):7502-7507. doi:10.1073/pnas.95.13.7502

29. Cianci R, Cammarota G, Frisullo G, Pagliari D, Ianiro G, Martini M, Frosali S, Plantone D, Damato V, Casciano F, Landolfi R, Paola Batocchi A, Pandolfi F (2012) Tissue-infiltrating lymphocytes analysis reveals large modifications of the duodenal "immunological niche" in coeliac disease after gluten-free diet. Clin Transl Gastroenterol 3:e28. doi:10.1038/ctg.2012.22

30. Cohen AD, Dreiher J, Birkenfeld S (2009) Psoriasis associated with ulcerative colitis and Crohn's disease. J Eur Acad Dermatol Venereol 23(5):561-565. doi:10.1111/j.1468-3083.2008.03031.x

31. Collamer AN, Battafarano DF (2010) Psoriatic skin lesions induced by tumor necrosis factor antagonist therapy: clinical features and possible immunopathogenesis. Semin Arthritis Rheum 40(3):233-240. doi:10.1016/j.semarthrit.2010.04.003

32. Collamer AN, Guerrero KT, Henning JS, Battafarano DF (2008) Psoriatic skin lesions induced by tumor necrosis factor antagonist therapy: a literature review and potential mechanisms of action. Arthritis Rheum 59(7):996-1001. doi:10.1002/art.23835

33. Collin P, Reunala T (2003) Recognition and management of the cutaneous manifestations of celiac disease: a guide for dermatologists. Am J Clin Dermatol 4(1):13-20. doi:10.2165/00128071-200304010-00002

34. Costa SC, Hirota SK, Takahashi MD, Andrade H Jr, Migliari DA (2009) Oral lesions in 166 patients with cutaneous psoriasis: a controlled study. Med Oral Patol Oral Cir Bucal 14(8):e371-e375

35. Cullen G, Kroshinsky D, Cheifetz AS, Korzenik JR (2011) Psoriasis associated with anti-tumour necrosis factor therapy in inflammatory bowel disease: a new series and a review of 120 cases from the literature. Aliment Pharmacol Ther 34(1112):1318-1327. doi:10.1111/j.1365-2036.2011.04866.x

36. Damasiewicz-Bodzek A, Wielkoszynski T (2008) Serologic markers of celiac disease in psoriatic patients. J Eur Acad Dermatol Venereol 22(9):1055-1061. doi:10.1111/j.1468-3083.2008.02713.x

37. Daneshpazhooh M, Moslehi H, Akhyani M, Etesami M (2004) Tongue lesions in psoriasis: a controlled study. BMC Dermatol 4(1):16. doi:10.1186/1471-5945-4-16

38. Darwazeh AM, Pillai K (1993) Prevalence of tongue lesions in 1013 Jordanian dental outpatients. Community Dent Oral Epidemiol 21(5):323-324. doi:10.1111/j.1600-0528.1993.tb00785.x

39. De Boer WA, Tytgat GN (1992) A patient with osteomalacia as single presenting symptom of gluten-sensitive enteropathy. J Intern Med 232(1):81-85. doi:10.1111/j.1365-2796.1992. tb00554.x 
40. de Gannes GC, Ghoreishi M, Pope J, Russell A, Bell D, Adams S, Shojania K, Martinka M, Dutz JP (2007) Psoriasis and pustular dermatitis triggered by TNF- $\{$ alpha $\}$ inhibitors in patients with rheumatologic conditions. Arch Dermatol 143(2):223231. doi:10.1001/archderm.143.2.223

41. D'Erme AM, Agnoletti AF, Prignano F (2013) Fissured tongue responding to biologics during the treatment of psoriasis: the importance of detecting oral involvement of psoriasis. Dermatol Ther 26(4):364-366. doi:10.1111/dth.12000

42. Di Cesare A, Di Meglio P, Nestle FO (2009) The IL-23/Th17 axis in the immunopathogenesis of psoriasis. J Invest Dermatol 129(6):1339-1350. doi:10.1038/jid.2009.59

43. dos Santos PJ, Bessa CF, de Aguiar MC, do Carmo MA (2004) Cross-sectional study of oral mucosal conditions among a central Amazonian Indian community, Brazil. J Oral Pathol Med 33(1):7-12. doi:10.1111/j.1600-0714.2004.00003.x

44. Duerr RH, Taylor KD, Brant SR, Rioux JD, Silverberg MS, Daly MJ, Steinhart AH, Abraham C, Regueiro M, Griffiths A, Dassopoulos T, Bitton A, Yang H, Targan S, Datta LW, Kistner EO, Schumm LP, Lee AT, Gregersen PK, Barmada MM, Rotter JI, Nicolae DL, Cho JH (2006) A genome-wide association study identifies IL23R as an inflammatory bowel disease gene. Science 314(5804): 1461-1463. doi:10.1126/science.1135245

45. Enlund F, Samuelsson L, Enerbäck C, Inerot A, Wahlström J, Yhr M, Torinsson A, Riley J, Swanbeck G, Martinsson T (1999) Psoriasis susceptibility locus in chromosome region $3 q 21$ identified in patients from southwest Sweden. Eur J Hum Genet 7(7):783-790. doi:10.1038/sj.ejhg.5200365

46. Farrell GC (2002) Drugs and steatohepatitis. Semin Liver Dis 22(2):185-194. doi:10.1055/s-2002-30106

47. Fatahzadeh M, Schwartz RA (2016) Oral psoriasis: an overlooked enigma. Dermatology 232(3):319-325. doi:10.1159/000444850

48. Femiano F (2001) Geographic tongue (migrant glossitis) and psoriasis. Minerva Stomatol 50(6):213-217

49. Ferrandiz C, Pujol RM, Garcia-Patos V, Bordas X, Smandia JA (2002) Psoriasis of early and late onset: a clinical and epidemiologic study from Spain. J Am Acad Dermatol 46(6):867-873. doi:10.1067/mjd.2002.120470

50. Fitch E, Harper E, Skorcheva I, Kurtz SE, Blauvelt A (2007) Pathophysiology of psoriasis: recent advances on IL-23 and Th17 cytokines. Curr Rheumatol Rep 9(6):461-467. doi:10.1007/ s11926-007-0075-1

51. Fitzpatrick LR (2013) Inhibition of IL-17 as a pharmacological approach for IBD. Int Rev Immunol 32:544-555. doi:10.3109/0 8830185.2013.821118

52. Frentz G, Olsen JH (1999) Malignant tumours and psoriasis: a follow-up study. Br J Dermatol 140(2):237-242. doi:10.1046/j.1365-2133.1999.02655.x

53. Frikha F, Snoussi M, Bahloul Z (2012) Osteomalacia associated with cutaneous psoriasis as the presenting feature of coeliac disease: a case report. Pan Afr Med J 11:58. doi:10.11604/ pamj.2012.11.58.1613

54. Funk J, Langeland T, Schrumpf E, Hanssen LE (1991) Psoriasis induced by interferon-alpha. Br J Dermatol 125(5):463-465. doi:10.1111/j.1365-2133.1991.tb14774.x

55. Ganzetti G, Campanati A, Santarelli A, Pozzi V, Molinelli E, Minnetti I, Brisigotti V, Procaccini M, Emanuelli M, Offidani A (2015) Involvement of the oral cavity in psoriasis: results of a clinical study. Br J Dermatol 172(1):282-285. doi:10.1111/ bjd.13201

56. Gilliet M, Conrad C, Geiges M, Cozzio A, Thürlimann W, Burg G, Nestle FO, Dummer R (2004) Psoriasis triggered by toll-like receptor 7 agonist imiquimod in the presence of dermal plasmacytoid dendritic cell precursors. Arch Dermatol 140(12):14901495. doi:10.1001/archderm.140.12.1490
57. Gisondi P, Cazzaniga S, Chimenti S, Giannetti A, Maccarone M, Picardo M, Girolomoni G, Naldi L, Psocare Study Group (2013) Metabolic abnormalities associated with initiation of systemic treatment for psoriasis: evidence from the Italian Psocare Registry. J Eur Acad Dermatol Venereol 27(1):1468-3083. doi:10.1111/j.1468-3083.2012.04450.x

58. Gisondi P, Del Giglio M, Cozzi A, Girolomoni G (2010) Psoriasis, the liver, and the gastrointestinal tract. Dermatol Ther 23(2):155-159. doi:10.1111/j.1529-8019.2010.01310.x

59. Gisondi P, Galvan A, Idolazzi L, Girolomoni G (2015) Management of moderate to severe psoriasis in patients with metabolic comorbidities. Front Med (Lausanne) 2:1. doi:10.3389/ fmed.2015.00001

60. Gisondi P, Targher G, Zoppini G, Girolomoni G (2009) Nonalcoholic fatty liver disease in patients with chronic plaque psoriasis. J Hepatol 51(4):758-764. doi:10.1016/j.jhep.2009.04.020

61. Gonzaga HF, Chaves MD, Gonzaga LH, Picciani BL, Jorge MA, Dias EP, Tomimori J (2015) Environmental factors in benign migratory glossitis and psoriasis: retrospective study of the association of emotional stress and alcohol and tobacco consumption with benign migratory glossitis and cutaneous psoriasis. J Eur Acad Dermatol Venereol 29(3):533-536. doi:10.1111/jdv.12616

62. Gonzaga HF, Marcos EV, Santana FC, Jorge MA, Tomimori J (2013) HLA alleles in Brazilian patients with fissured tongue. J Eur Acad Dermatol Venereol 27(2):1468-3083. doi:10.1111/j.1468-3083.2012.04537.x

63. Gonzaga HF, Torres EA, Alchorne MM, Gerbase-Delima M (1996) Both psoriasis and benign migratory glossitis are associated with HLA-Cw6. Br J Dermatol 135(3):368-370. doi:10.1046/j.1365-2133.1996.d01-1006.x

64. Goswami M, Verma A, Verma M (2012) Benign migratory glossitis with fissured tongue. J Indian Soc Pedod Prev Dent 30(2):173-175. doi:10.4103/0970-4388.100008

65. Gottlieb AB, Chao C, Dann F (2008) Psoriasis comorbidities. J Dermatol Treat 19(1):5-21. doi:10.1080/09546630701364768

66. Gottlieb AB, Evans R, Li S, Dooley LT, Guzzo CA, Baker D, Bala M, Marano CW, Menter A (2004) Infliximab induction therapy for patients with severe plaque-type psoriasis: a randomized, double-blind, placebo-controlled trial. J Am Acad Dermatol 51(4):534-542. doi:10.1016/j.jaad.2004.02.021

67. Guerra I, Algaba A, Pérez-Calle JL, Chaparro M, Marín-Jiménez I, García-Castellanos R, González-Lama Y, López-Sanromán A, Manceñido N, Martínez-Montiel P, Quintanilla E, Taxonera C, Villafruela M, Romero-Maté A, López-Serrano P, Gisbert JP, Bermejo $F$ (2012) Induction of psoriasis with anti-TNF agents in patients with inflammatory bowel disease: a report of 21 cases. J Crohns Colitis 6(5):518-523. doi:10.1016/j.crohns.2011.10.007

68. Guimaraes AL, Correia-Silva Jde F, Diniz MG, Xavier GM, Horta MC, Gomez RS (2007) Investigation of functional gene polymorphisms: IL-1B, IL-6 and TNFA in benign migratory glossitis in Brazilian individuals. J Oral Pathol Med 36(9):533537. doi:10.1111/j.1600-0714.2007.00559.x

69. Hafström I, Ringertz B, Spångberg A, von Zweigbergk L, Brannemark S, Nylander I, Rönnelid J, Laasonen L, Klareskog L (2001) A vegan diet free of gluten improves the signs and symptoms of rheumatoid arthritis: the effects on arthritis correlate with a reduction in antibodies to food antigens. Rheumatology 40(10):1175-1179. doi:10.1093/rheumatology/40.10.1175

70. Hammer B, Ashurst P, Naish J (1968) Diseases associated with ulcerative colitis and Crohn's disease. Gut 9(1):17-21

71. Hannuksela-Svahn A, Pukkala E, Laara E, Poikolainen K, Karvonen J (2000) Psoriasis, its treatment, and cancer in a cohort of Finnish patients. J Invest Dermatol 114(3):587-590. doi:10.1046/j.1523-1747.2000.00898.x

72. Hardwick RN, Clarke JD, Lake AD, Canet MJ, Anumol T, Street SM, Merrell MD, Goedken MJ, Snyder SA, Cherrington NJ 
(2014) Increased susceptibility to methotrexate-induced toxicity in nonalcoholic steatohepatitis. Toxicol Sci 142(1):45-55. doi:10.1093/toxsci/kfu156

73. Harrison MJ, Dixon WG, Watson KD, King Y, Groves R, Hyrich KL, Symmons DP, British Society for Rheumatology Biologics Register Control Centre Consortium, BSRBR (2009) Rates of new-onset psoriasis in patients with rheumatoid arthritis receiving anti-tumour necrosis factor alpha therapy: results from the British Society for Rheumatology Biologics Register. Ann Rheum Dis 68(2):209-215. doi:10.1136/ard.2007.087288

74. Henseler T, Christophers E (1985) Psoriasis of early and late onset: characterization of two types of psoriasis vulgaris. J Am Acad Dermatol 13(3):450-456. doi:10.1016/ S0190-9622(85)70188-0

75. Hernández-Pérez F, Jaimes-Aveldañez A, Urquizo-Ruvalcaba Mde L, Díaz-Barcelot M, Irigoyen-Camacho ME, Vega-Memije ME, Mosqueda-Taylor A (2008) Prevalence of oral lesions in patients with psoriasis. Med Oral Patol Oral Cir Bucal 13(11):E703-E708

76. Hirahara K, Liu L, Clark RA, Yamanaka K, Fuhlbrigge RC, Kupper TS (2006) The majority of human peripheral blood CD4+ CD25highFoxp3+ regulatory $\mathrm{T}$ cells bear functional skinhoming receptors. J Immunol 177(7):4488-4494. doi:10.4049/ jimmunol.177.7.4488

77. Honarmand M, Farhad Mollashahi L, Shirzaiy M, Sehhatpour M (2013) Geographic tongue and associated risk factors among iranian dental patients. Iran J Public Health 42(2):215-219

78. Hugot JP, Chamaillard M, Zouali H, Lesage S, Cézard JP, Belaiche J, Almer S, Tysk C, O'Morain CA, Gassull M, Binder V, Finkel Y, Cortot A, Modigliani R, Laurent-Puig P, GowerRousseau C, Macry J, Colombel JF, Sahbatou M, Thomas G (2001) Association of NOD2 leucine-rich repeat variants with susceptibility to Crohn's disease. Nature 411(6837):599-603. doi:10.1038/35079107

79. Hugot JP, Laurent-Puig P, Gower-Rousseau C, Olson JM, Lee JC, Beaugerie L, Naom I, Dupas JL, Van Gossum A, Orholm M, Bonaiti-Pellie C, Weissenbach J, Mathew CG, Lennard-Jones JE, Cortot A, Colombel JF, Thomas G (1996) Mapping of a susceptibility locus for Crohn's disease on chromosome 16. Nature 379(6568):821-823. doi:10.1038/379821a0

80. Humbert P, Bidet A, Treffel P, Drobacheff C, Agache P (1991) Intestinal permeability in patients with psoriasis. J Dermatol Sci 2(4):324-326

81. Hunter CA, Jones SA (2015) IL-6 as a keystone cytokine in health and disease. Nat Immunol 16(5):448-457. doi:10.1038/ ni. 3153

82. Iborra M, Beltran B, Bastida G, Aguas M, Nos P (2011) Infliximab and adalimumab-induced psoriasis in Crohn's disease: a paradoxical side effect. J Crohns Colitis 5(2):157-161. doi:10.1016/j.crohns.2010.11.001

83. Iltanen S, Collin P, Korpela M, Holm K, Partanen J, Polvi A, Mäki M (1999) Celiac disease and markers of celiac disease latency in patients with primary Sjogren's syndrome. Am J Gastroenterol 94(4):1042-1046. doi:10.1111/j.1572-0241.1999.01011.x

84. Ishibashi M, Tojo G, Watanabe M, Tamabuchi T, Masu T, Aiba S (2010) Geographic tongue treated with topical tacrolimus. J Dermatol Case Rep 4(4):57-59. doi:10.3315/jdcr.2010.1058

85. Jainkittivong A, Langlais RP (2005) Geographic tongue: clinical characteristics of 188 cases. J Contemp Dent Pract 6(1):123-135

86. Ji J, Shu X, Sundquist K, Sundquist J, Hemminki K (2009) Cancer risk in hospitalized psoriasis patients: a follow-up study in Sweden. Br J Cancer 100(9):1499-1502. doi:10.1038/ sj.bjc. 6605027

87. Juzlova K, Votrubova J, Dzambova M, Gopfertova D, Hercogova J, Smerhovsky Z (2016) Gastrointestinal comorbidities in patients with psoriasis in the Czech Republic: the results of
189 patients with psoriasis and 378 controls. Biomed Pap Med Fac Univ Palacky Olomouc Czech Repub 160(1):100-105. doi:10.5507/bp.2015.048

88. Kalb RE, Strober B, Weinstein G, Lebwohl M (2009) Methotrexate and psoriasis: 2009 national psoriasis foundation consensus conference. J Am Acad Dermatol 60(5):824-837. doi:10.1016/j.jaad.2008.11.906

89. Kia KF, Nair RP, Ike RW, Hiremagalore R, Elder JT, Ellis CN (2007) Prevalence of antigliadin antibodies in patients with psoriasis is not elevated compared with controls. Am J Clin Dermatol 8(5):301-305. doi:10.2165/00128071-200708050-00005

90. Ko JM, Gottlieb AB, Kerbleski JF (2009) Induction and exacerbation of psoriasis with TNF-blockade therapy: a review and analysis of 127 cases. J Dermatol Treat 20(2):100-108. doi:10.1080/09546630802441234

91. Kupfer SS, Jabri B (2012) Pathophysiology of celiac disease. Gastrointest Endosc Clin N Am 22(4):639-660. doi:10.1016/j. giec.2012.07.003

92. Kupper C (2005) Dietary guidelines and implementation for celiac disease. Gastroenterology 128(4 Suppl 1):121-127. doi:10.1053/j.gastro.2005.02.024

93. Ladoyanni E, Nambi R (2005) Psoriasis exacerbated by interferon-alpha in a patient with chronic myeloid leukemia. J Drugs Dermatol 4(2):221-222

94. Lannan S, McLean A, Drost E, Gillooly M, Donaldson K, Lamb D, MacNee W (1992) Changes in neutrophil morphology and morphometry following exposure to cigarette smoke. Int J Exp Pathol 73(2):183-191

95. Lee E, Trepicchio WL, Oestreicher JL, Pittman D, Wang F, Chamian F, Dhodapkar M, Krueger JG (2004) Increased expression of interleukin $23 \mathrm{p} 19$ and p40 in lesional skin of patients with psoriasis vulgaris. J Exp Med 199(1):125-130. doi: 10.1084/jem.20030451

96. Lee FI, Bellary SV, Francis C (1990) Increased occurrence of psoriasis in patients with Crohn's disease and their relatives. Am J Gastroenterol 85(8):962-963. doi:10.1111/j.1572-0241.1990.tb06788.x

97. Lee HH, Song IH, Friedrich M, Gauliard A, Detert J, Röwert J, Audring H, Kary S, Burmester GR, Sterry W, Worm M (2007) Cutaneous side-effects in patients with rheumatic diseases during application of tumour necrosis factor-alpha antagonists. Br J Dermatol 156(3):486-491. doi:10.1111/j.1365-2133.2007.07682.x

98. Lehmann B (2009) Role of the vitamin D3 pathway in healthy and diseased skin - facts, contradictions and hypotheses. Exp Dermatol 18(2):97-108. doi:10.1111/j.1600-0625.2008.00810.x

99. León AJ, Garrote JA, Blanco-Quirós A, Calvo C, FernándezSalazar L, Del Villar A, Barrera A, Arranz E (2006) Interleukin 18 maintains a long-standing inflammation in coeliac disease patients. Clin Exp Immunol 146(3):479-485. doi:10.1111/j.1365-2249.2006.03239.x

100. Li WQ, Han JL, Chan AT, Qureshi AA (2013) Psoriasis, psoriatic arthritis and increased risk of incident Crohn's disease in US women. Ann Rheum Dis 72(7):1200-1205. doi:10.1136/ annrheumdis-2012-202143

101. Lima Ede A, Lima Mde A (2011) Reviewing concepts in the immunopathogenesis of psoriasis. An Bras Dermatol 86(6):1151-1158. doi:10.1590/S0365-05962011000600014

102. Lindqvist U, Rudsander A, Boström A, Nilsson B, Michaëlsson $\mathrm{G}$ (2002) IgA antibodies to gliadin and coeliac disease in psoriatic arthritis. Rheumatology 41(1):31-37. doi:10.1093/ rheumatology/41.1.31

103. Loria P, Carulli L, Bertolotti M, Lonardo A (2009) Endocrine and liver interaction: the role of endocrine pathways in NASH. Nat Rev Gastroenterol Hepatol 6(4):236-247. doi:10.1038/ nrgastro.2009.33 
104. Loria P, Lonardo A, Bellentani S, Day CP, Marchesini G, Carulli N (2007) Non-alcoholic fatty liver disease (NAFLD) and cardiovascular disease: an open question. Nutr Metab Cardiovasc Dis 17(9):684-698. doi:10.1016/j.numecd.2007.01.007

105. Lu Y, Chen H, Nikamo P, Qi Low H, Helms C, Seielstad M, Liu J, Bowcock AM, Stahle M, Liao W (2013) Association of cardiovascular and metabolic disease genes with psoriasis. J Invest Dermatol 133(3):836-839. doi:10.1038/jid.2012.366

106. Ludvigsson JF, Lindelof B, Zingone F, Ciacci C (2011) Psoriasis in a nationwide cohort study of patients with celiac disease. $\mathrm{J}$ Invest Dermatol 131(10):2010-2016. doi:10.1038/jid.2011.162

107. Mantovani A, Gisondi P, Lonardo A, Targher G (2016) Relationship between non-alcoholic fatty liver disease and psoriasis: a novel hepato-dermal axis? Int J Mol Sci. doi:10.3390/ ijms 17020217

108. Margolis D, Bilker W, Hennessy S, Vittorio C, Santanna J, Strom BL (2001) The risk of malignancy associated with psoriasis. Arch Dermatol 137(6):778-783

109. Matthews D, Fry L, Powles A, Weber J, McCarthy M, Fisher E, Davies K, Williamson R (1996) Evidence that a locus for familial psoriasis maps to chromosome 4q. Nat Genet 14(2):231-233. doi:10.1038/ng1096-231

110. Mattsson U, Warfvinge G, Jontell M (2015) Oral psoriasisa diagnostic dilemma: a report of two cases and a review of the literature. Oral Surg Oral Med Oral Pathol Oral Radiol 120(4):e183-e189. doi:10.1016/j.oooo.2015.03.005

111. Menter A, Tyring SK, Gordon K, Kimball AB, Leonardi CL, Langley RG, Strober BE, Kaul M, Gu Y, Okun M, Papp K (2008) Adalimumab therapy for moderate to severe psoriasis: a randomized, controlled phase III trial. J Am Acad Dermatol 58(1):106-115. doi:10.1016/j.jaad.2007.09.010

112. Michaelsson G, Ahs S, Hammarstrom I, Lundin IP, Hagforsen E (2003) Gluten-free diet in psoriasis patients with antibodies to gliadin results in decreased expression of tissue transglutaminase and fewer Ki67+ cells in the dermis. Acta Derm Venereol 83(6):425-429. doi:10.1080/00015550310015022

113. Michaelsson G, Gerden B, Hagforsen E, Nilsson B, Pihl-Lundin I, Kraaz W et al (2000) Psoriasis patients with antibodies to gliadin can be improved by a gluten-free diet. Br J Dermatol 142(1):44-51. doi:10.1046/j.1365-2133.2000.03240.x

114. Michaelsson G, Kajermo U, Michaelsson A, Hagforsen E (2005) Infliximab can precipitate as well as worsen palmoplantar pustulosis: possible linkage to the expression of tumour necrosis factor-alpha in the normal palmar eccrine sweat duct? Br J Dermatol 153(6):1243-1244. doi:10.1111/j.1365-2133.2005.06977.x

115. Miele L, Vallone S, Cefalo C, La Torre G, Di Stasi C, Vecchio FM, D’Agostino M, Gabrieli ML, Vero V, Biolato M, Pompili M, Gasbarrini G, Rapaccini G, Amerio P, De Simone C, Grieco A (2009) Prevalence, characteristics and severity of non-alcoholic fatty liver disease in patients with chronic plaque psoriasis. J Hepatol 51(4):778-786. doi:10.1016/j.jhep.2009.06.008

116. Migliari DA, Penha SS, Marques MM, Matthews RW (2004) Considerations on the diagnosis of oral psoriasis: a case report. Med Oral 9(4):300-303

117. Miloğlu O, Göregen M, Akgül HM, Acemoğlu H (2009) The prevalence and risk factors associated with benign migratory glossitis lesions in 7619 Turkish dental outpatients. Oral Surg Oral Med Oral Pathol Oral Radiol Endod 107(2):29-33. doi:10.1016/j.tripleo.2008.10.015

118. Montesu MA, Dessi-Fulgheri C, Pattaro C, Ventura V, Satta R, Cottoni F (2011) Association between psoriasis and coeliac disease? A case-control study. Acta Derm Venereol 91(1):92-93. doi:10.2340/00015555-0960

119. Nair RP, Henseler T, Jenisch S, Stuart P, Bichakjian CK, Lenk W, Westphal E, Guo SW, Christophers E, Voorhees JJ, Elder JT (1997) Evidence for two psoriasis susceptibility loci
(HLA and $17 \mathrm{q}$ ) and two novel candidate regions (16q and 20 ) by genome-wide scan. Hum Mol Genet 6(8):1349-1356. doi:10.1093/hmg/6.8.1349

120. Nestle FO, Conrad C, Tun-Kyi A, Homey B, Gombert M, Boyman O et al (2005) Plasmacytoid predendritic cells initiate psoriasis through interferon-alpha production. J Exp Med 202(1):135-143. doi:10.1084/jem.20050500

121. Ogura Y, Bonen DK, Inohara N, Nicolae DL, Chen FF, Ramos R, Britton H, Moran T, Karaliuskas R, Duerr RH, Achkar JP, Brant SR, Bayless TM, Kirschner BS, Hanauer SB, Nuñez G, Cho JH (2001) A frameshift mutation in NOD2 associated with susceptibility to Crohn's disease. Nature 411(6837):603-606. doi:10.1038/35079114

122. Ojetti V, Aguilar Sanchez J, Guerriero C, Fossati B, Capizzi R, De Simone C, Migneco A, Amerio P, Gasbarrini G, Gasbarrini A (2003) High prevalence of celiac disease in psoriasis. Am J Gastroenterol 98(11):2574-2575. doi:10.1111/j.1572-0241.2003.08684.x

123. Paimela L, Kurki P, Leirisalo-Repo M, Piirainen H (1995) Gliadin immune reactivity in patients with rheumatoid arthritis. Clin Exp Rheumatol 13(5):603-607

124. Palucka AK, Blanck JP, Bennett L, Pascual V, Banchereau J (2005) Cross-regulation of TNF and IFN-alpha in autoimmune diseases. Proc Natl Acad Sci USA 102(9):3372-3377. doi:10.1073/pnas.0408506102

125. Parisi R, Symmons DP, Griffiths CE, Ashcroft DM (2013) Global epidemiology of psoriasis: a systematic review of incidence and prevalence. J Invest Dermatol 133(2):377-385. doi:10.1038/jid.2012.339

126. Paul CF, Ho VC, McGeown C, Christophers E, Schmidtmann B, Guillaume JC, Lamarque V, Dubertret L (2003) Risk of malignancies in psoriasis patients treated with cyclosporine: a 5 y cohort study. J Invest Dermatol 120(2):211-216. doi:10.1046/j.1523-1747.2003.12040.x

127. Picciani B, Silva-Junior G, Carneiro S, Sampaio AL, Goldemberg DC, Oliveira J, Porto LC, Dias EP (2012) Geographic stomatitis: an oral manifestation of psoriasis? J Dermatol Case Rep 6(4):113-116. doi:10.3315/jdcr.2012.1118

128. Picciani BL, Domingos TA, Teixeira-Souza T, Santos Vde C, Gonzaga HF, Cardoso-Oliveira J, Gripp AC, Dias EP, Carneiro S (2016) Geographic tongue and psoriasis: clinical, histopathological, immunohistochemical and genetic correlation-a literature review. An Bras Dermatol 91(4):410-421. doi:10.1590/ abd1806-4841.20164288

129. Picciani BL, Silva-Junior GO, Michalski-Santos B, Avelleira JC, Azulay DR, Pires FR, Dias EP, Cantisano MH (2011) Prevalence of oral manifestations in 203 patients with psoriasis. J Eur Acad Dermatol Venereol 25(12):1481-1483. doi:10.1111/j.1468-3083.2010.03936.x

130. Picciani BLS, Souza TT, Santos VCB, Domingos TA, Carneiro $\mathrm{S}$, Avelleira JC et al (2015) Geographic tongue and fissured tongue in 348 patients with psoriasis: correlation with disease severity. Sci World J 564326:1-7. doi:10.1155/2015/564326

131. Pogrel MA, Cram D (1988) Intraoral findings in patients with psoriasis with a special reference to ectopic geographic tongue (erythema circinata). Oral Surg Oral Med Oral Pathol 66(2):184-189. doi:10.1016/0030-4220(88)90091-6

132. Pouplard C, Brenaut E, Horreau C, Barnetche T, Misery L, Richard MA, Aractingi S, Aubin F, Cribier B, Joly P, Jullien D, Le Maître M, Ortonne JP, Paul C (2013) Risk of cancer in psoriasis: a systematic review and meta-analysis of epidemiological studies. J Eur Acad Dermatol Venereol 3:36-46. doi:10.1111/jdv. 12165

133. Prignano F, D’Erme AM, Bonciolini V, Lotti T (2011) Mucosal psoriasis: a new insight toward a systemic 
inflammatory disease. Int J Dermatol 50(12):1579-1581. doi:10.1111/j.1365-4632.2010.04864.x

134. Prizment AE, Alonso A, Folsom AR, Ahmed RL, Virnig BA, Warshaw EM, Anderson KE (2011) Association between psoriasis and incident cancer: the Iowa's Women's Health Study. Cancer Causes Control 22(7):1003-1010. doi:10.1007/ s10552-011-9773-0

135. Rahier JF, Buche S, Peyrin-Biroulet L, Bouhnik Y, Duclos B, Louis E, Papay P, Allez M, Cosnes J, Cortot A, Laharie D, Reimund JM, Lémann M, Delaporte E, Colombel JF, Groupe d'Etude Thérapeutique des Affections Inflammatoires du Tube Digestif (GETAID) (2010) Severe skin lesions cause patients with inflammatory bowel disease to discontinue anti-tumor necrosis factor therapy. Clin Gastroenterol Hepatol 8(12):10481055. doi:10.1016/j.cgh.2010.07.022

136. Rensch MJ, Szyjkowski R, Shaffer RT, Fink S, Kopecky C, Grissmer L, Enzenhauer R, Kadakia S (2001) The prevalence of celiac disease autoantibodies in patients with systemic lupus erythematosus. Am J Gastroenterol 96(4):1113-1115. doi:10.1111/j.1572-0241.2001.03753.x

137. Rodrigo L (2006) Celiac disease. World J Gastroenterol 12(41):6585-6593. doi:10.3748/WJG.v12.i41.6585

138. Rogers RS 3rd, Bruce AJ (2004) The tongue in clinical diagnosis. J Eur Acad Dermatol Venereol 18(3):254-259. doi:10.1111/j.1468-3083.2004.00769.x

139. Rosenberg P, Urwitz H, Johannesson A, Ros AM, Lindholm J, Kinnman N, Hultcrantz R (2007) Psoriasis patients with diabetes type 2 are at high risk of developing liver fibrosis during methotrexate treatment. J Hepatol 46(6):1111-1118. doi:10.1016/j. jhep.2007.01.024

140. Rostami K, Aldulaimi D, Holmes G, Johnson MW, Robert M, Srivastava A, Fléjou JF, Sanders DS, Volta U, Derakhshan MH, Going JJ, Becheanu G, Catassi C, Danciu M, Materacki L, Ghafarzadegan K, Ishaq S, Rostami-Nejad M, Peña AS, Bassotti G, Marsh MN, Villanacci V (2015) Microscopic enteritis: bucharest consensus. World J Gastroenterol 21(9):2593-2604. doi:10.3748/wjg.v21.i9.2593

141. Rostom A, Murray JA, Kagnoff MF (2006) American Gastroenterological Association (AGA) Institute technical review on the diagnosis and management of celiac disease. Gastroenterology 131(6):1981-2002. doi:10.1053/j.gastro.2006.10.004

142. Sabat R, Philipp S, Hoflich C, Kreutzer S, Wallace E, Asadullah K, Volk HD, Sterry W, Wolk K (2007) Immunopathogenesis of psoriasis. Exp Dermatol 16(10):779-798. doi:10.1111/j.1600-0625.2007.00629.x

143. Salvati VM, MacDonald TT, Bajaj-Elliott M, Borrelli M, Staiano A, Auricchio S, Troncone R, Monteleone G (2002) Interleukin 18 and associated markers of $\mathrm{T}$ helper cell type 1 activity in coeliac disease. Gut 50(2):186-190. doi:10.1136/gut.50.2.186

144. Saruta M, Yu QT, Fleshner PR, Mantel PY, Schmidt-Weber CB, Banham AH, Papadakis KA (2007) Characterization of FOXP3+ CD4+ regulatory T cells in Crohn's disease. Clin Immunol 125(3):281-290. doi:10.1016/j.clim.2007.08.003

145. Satsangi J, Parkes M, Louis E, Hashimoto L, Kato N, Welsh K, Terwilliger JD, Lathrop GM, Bell JI, Jewell DP (1996) Two stage genome-wide search in inflammatory bowel disease provides evidence for susceptibility loci on chromosomes 3, 7 and 12. Nat Genet 14(2):199-202. doi:10.1038/ng1096-199

146. Saurat JH, Stingl G, Dubertret L, Papp K, Langley RG, Ortonne JP, Unnebrink K, Kaul M, Camez A, CHAMPION Study Investigators (2008) Efficacy and safety results from the randomized controlled comparative study of adalimumab vs. methotrexate vs. placebo in patients with psoriasis (CHAMPION). Br J Dermatol 158(3):558-566. doi:10.1111/j.1365-2133.2007.08315.x

147. Sfikakis PP, Iliopoulos A, Elezoglou A, Kittas C, Stratigos A (2005) Psoriasis induced by anti-tumor necrosis factor therapy: a paradoxical adverse reaction. Arthritis Rheum 52(8):2513-2518. doi:10.1002/art.21233

148. Shoelson SE, Lee J, Goldfine AB (2006) Inflammation and insulin resistance. J Clin Invest 116(7):1793-1801. doi:10.1172/ JCI29069

149. Shulman GI (2014) Ectopic fat in insulin resistance, dyslipidemia, and cardiometabolic disease. N Engl J Med 371(23):2237-2238. doi:10.1056/NEJMc1412427

150. Singh S, Nivash S, Mann BK (2013) Matched case-control study to examine association of psoriasis and migratory glossitis in India. Indian J Dermatol Venereol Leprol 79(1):59-64. doi:10.4103/0378-6323.104670

151. Skavland J, Shewry PR, Marsh J, Geisner B, Marcusson JA (2012) In vitro screening for putative psoriasis-specific antigens among wheat proteins and peptides. Br J Dermatol 166(1):67-73. doi:10.1111/j.1365-2133.2011.10608.x

152. Skroza N, Skroza N, Proietti I, Pampena R (2013) Correlations between psoriasis and inflammatory bowel diseases. Biomed Res Int 2013:983902

153. Stefan N, Haring HU (2013) The role of hepatokines in metabolism. Nat Rev Endocrinol 9(3):144-152. doi:10.1038/ nrendo.2012.258

154. Taccari E, Spada S, Giuliani A, Sorgi ML, Pecorella I, Onetti Muda A (2002) Co-occurrence of psoriatic arthritis with collagenous colitis: clinicopathologic findings of a case. Clin Rheumatol 21(4):335-338. doi:10.1007/s100670200088

155. Targher G, Marra F, Marchesini G (2008) Increased risk of cardiovascular disease in non-alcoholic fatty liver disease: causal effect or epiphenomenon? Diabetologia 51(11):1947-1953. doi:10.1007/s00125-008-1135-4

156. Tesmer LA, Lundy SK, Sarkar S, Fox DA (2008) Th17 cells in human disease. Immunol Rev 223:87-113. doi:10.1111/j.1600-065X.2008.00628.X

157. Tichy M, Hercogova J (2014) Manifestation of Crohn's disease in a young woman during the course of treatment for severe form of chronic plaque psoriasis with etanercept. Dermatol Ther 27(4):211-214. doi:10.1111/dth.12119

158. Triantafillidis JK, Malgarinos G (2013) Severe psoriasis preceding diagnosis of large bowel Crohn's disease for 15 years. J Crohns Colitis 7(2):e80. doi:10.1016/j.crohns.2012.07.014

159. Trynka G, Hunt KA, Bockett NA, Romanos J, Mistry V, Szperl A et al (2011) Dense genotyping identifies and localizes multiple common and rare variant association signals in celiac disease. Nat Genet 43(12):1193-1201. doi:10.1038/ng.998

160. Tsai TF, Wang TS, Hung ST, Tsai PI, Schenkel B, Zhang M, Tang CH (2011) Epidemiology and comorbidities of psoriasis patients in a national database in Taiwan. J Dermatol Sci 63(1):40-46. doi:10.1016/j.jdermsci.2011.03.002

161. Tsoi LC, Spain SL, Knight J, Ellinghaus E, Stuart PE, Capon F et al (2012) Identification of 15 new psoriasis susceptibility loci highlights the role of innate immunity. Nat Genet 44(12):13411348. doi: $10.1038 / \mathrm{ng} .2467$

162. Tursi A, Elisei W, Giorgetti GM, Gaspardone A, Lecca PG, Di Cesare L, Brandimarte G (2010) Prevalence of celiac disease and symptoms in relatives of patients with celiac disease. Eur Rev Med Pharmacol Sci 14(6):567-572

163. Tuzun B, Wolf R, Tuzun Y, Serdaroglu S (2000) Recurrent aphthous stomatitis and smoking. Int J Dermatol 39(5):358-360. doi:10.1046/j.1365-4362.2000.00963.x

164. Ucak S, Ekmekci TR, Basat O, Koslu A, Altuntas Y (2006) Comparison of various insulin sensitivity indices in psoriatic patients and their relationship with type of psoriasis. J Eur Acad Dermatol Venereol 20(5):517-522. doi:10.1111/j.1468-3083.2006.01499.x

165. Ulmansky M, Michelle R, Azaz B (1995) Oral psoriasis: report of six new cases. J Oral Pathol Med 24(1):42-45. doi:10.1111/j.1600-0714.1995.tb01128.x 
166. van Schaik FD, Oldenburg B, Hart AR, Siersema PD, Lindgren S, Grip O, Teucher B, Kaaks R, Bergmann MM, Boeing H, Carbonnel F, Jantchou P, Boutron-Ruault MC, Tjønneland A, Olsen A, Crowe FL, Peeters PH, van Oijen MG, Bueno-de-Mesquita HB (2013) Serological markers predict inflammatory bowel disease years before the diagnosis. Gut 62(5):683-688. doi:10.1136/ gutjnl-2012-302717

167. Vedak P, Kroshinsky D, St John J, Xavier RJ, Yajnik V, Ananthakrishnan AN (2016) Genetic basis of TNF-alpha antagonist associated psoriasis in inflammatory bowel diseases: a genotypephenotype analysis. Aliment Pharmacol Ther 43(6):697-704. doi:10.1111/apt.13542

168. Vlachos C, Gaitanis G, Katsanos KH, Christodoulou DK, Tsianos E, Bassukas ID (2016) Psoriasis and inflammatory bowel disease-links and risks. Psoriasis Targets Ther 6:73-92. doi:10.2147/PTT/S85194

169. Wiedermann CJ, Zelger A (2007) Lymphocytic colitis in a patient with psoriasis responsive to budesonide. Scand J Gastroentero 42(4):538-539. doi:10.1080/00365520600994400

170. Wolf N, Quaranta M, Prescott NJ, Allen M, Smith R, Burden AD, Worthington J, Griffiths CE, Mathew CG, Barker JN, Capon F, Trembath RC (2008) Psoriasis is associated with pleiotropic susceptibility loci identified in type II diabetes and Crohn disease. J Med Genet 45(2):114-116. doi:10.1136/jmg.2007.053595

171. Wollina U, Hansel G, Koch A, Schonlebe J, Kostler E, Haroske G (2008) Tumor necrosis factor-alpha inhibitor-induced psoriasis or psoriasiform exanthemata: first 120 cases from the literature including a series of six new patients. Am J Clin Dermatol 9(1):1-14

172. Woo WK, McMillan SA, Watson RG, McCluggage WG, Sloan JM, McMillan JC (2004) Coeliac disease-associated antibodies correlate with psoriasis activity. Br J Dermatol 151(4):891-894. doi:10.1111/j.1365-2133.2004.06137.x

173. Xing X, Liang Y, Sarkar MK, Wolterink L, Swindell WR, Voorhees JJ, Harms PW, Kahlenberg JM, Johnston A, Gudjonsson JE (2016) IL-17 responses are the dominant inflammatory signal linking inverse, erythrodermic, and chronic plaque psoriasis. J Invest Dermatol 136(12):2498-2501. doi:10.1016/j. jid.2016.07.008

174. Yang H, Plevy SE, Taylor K, Tyan D, Fischel-Ghodsian N, McElree C, Targan SR, Rotter JI (1999) Linkage of Crohn's disease to the major histocompatibility complex region is detected by multiple non-parametric analyses. Gut 44(4):519-526. doi:10.1136/ gut.44.4.519

175. Yesudian PD, Chalmers RJ, Warren RB, Griffiths CE (2012) In search of oral psoriasis. Arch Dermatol Res 304(1):1-5. doi:10.1007/s00403-011-1175-3

176. Younai FS, Phelan JA (1997) Oral mucositis with features of psoriasis: report of a case and review of the literature. Oral Surg Oral
Med Oral Pathol Oral Radiol Endod 84(1):61-67. doi:10.1016/ S1079-2104(97)90297-3

177. Young HS, Summers AM, Bhushan M, Brenchley PE, Griffiths CE (2004) Single-nucleotide polymorphisms of vascular endothelial growth factor in psoriasis of early onset. J Invest Dermatol 122(1):209-215. doi:10.1046/j.0022-202X.2003.22107.x

178. Young Park J, Hyun Rim J, Beom Choe Y, Il Youn J (2004) Facial psoriasis: comparison of patients with and without facial involvement. J Am Acad Dermatol 50(4):582-584. doi:10.1016/ S0190

179. Yu QT, Saruta M, Avanesyan A, Fleshner PR, Banham AH, Papadakis KA (2007) Expression and functional characterization of FOXP3+ CD4+ regulatory T cells in ulcerative colitis. Inflamm Bowel Dis 13(2):191-199. doi:10.1002/ibd.20053

180. Zadik Y, Drucker S, Pallmon S (2011) Migratory stomatitis (ectopic geographic tongue) on the floor of the mouth. J Am Acad Dermatol 65(2):459-460. doi:10.1016/j.jaad.2010.04.016

181. Zandman-Goddard G, Peeva E, Shoenfeld Y (2007) Gender and autoimmunity. Autoimmun Rev 6(6):366-372. doi:10.1016/j. autrev.2006.10.001

182. Zargari O (2006) The prevalence and significance of fissured tongue and geographical tongue in psoriatic patients. Clin Exp Dermatol 31(2):192-195. doi:10.1111/j.1365-2230.2005.02028.x

\section{Related articles recently published in Archives of Dermatological Research (selected by the journal's editorial staff)}

183. Ottas A, Fishman D, Okas TL, Kingo K, Soomets U (2017) The metabolic analysis of psoriasis identifies the associated metabolites while providing computational models for the monitoring of the disease. Arch Dermatol Res. doi:10.1007/s00403-017-1760-1

184. Hambly R, Kirby B (2017) The relevance of serum vitamin D in psoriasis: a review. Arch Dermatol Res. doi:10.1007/ s00403-017-1751-2

185. Mysliwiec H, Baran A, Harasim-Symbor E, Mysliwiec P, Milewska AJ, Chabowski A, Flisiak I (2017) Serum fatty acid profile in psoriasis and its comorbidity. Arch Dermatol Res 309:371-380

186. Zander N, Schafer I, Radtke M, Jacobi A, Heigel H, Augustin M (2017) Dermatological comorbidity in psoriasis: results from a large-scale cohort of employees. Arch Dermatol Res 309:349-356

187. Gutknecht M, Krensel M, Augustin M (2016) Health economic analyses of psoriasis management: a systematic literature search. Arch Dermatol Res 308:601-616 